Check for updates

1 University of Bristol Population Health Sciences and UK National Screening Programmes, Bristol, UK

2 London, UK

Correspondence to: A E Raffle angela.raffle@bristol.ac.uk Cite this as: BMJ 2021;373:n1058 http://dx.doi.org/10.1136/bmj.n1058 Published: 28 April 2021

\section{Mass screening for asymptomatic SARS-CoV-2 infection}

\author{
A misguided policy, unlikely to reduce transmission
}

\section{Angela E Raffle, ${ }^{1}$ Mike Gill ${ }^{2}$}

Project Moonshot ${ }^{1}$ has now extended to twice weekly self-testing at home for all adults in England, and soon Scotland. ${ }^{2}$ Yet the UK is already performing more coronavirus tests per case detected than anywhere in the world 3 with little effect according to the Public Accounts Committee. ${ }^{4}$ The cost and benefit from adding universal testing are unknown, and no plans are in place to measure them.

In 60 years of screening healthy people, effectiveness has never yet been achieved just by offering tests. What matters is a tightly designed pathway that can be shown to deliver positive outcomes in real life. Forty million cervical cytology screening tests from 1964 to 1985 achieved no net benefit. ${ }^{5}$ Deaths from cervical cancer fell only after the introduction of a quality assured programme that reached those at highest risk and took appropriate action after each test result. ${ }^{6}$

Ten years of infant phenylketonuria screening similarly had no impact until systems and quality assurance were introduced. ${ }^{7}$ Response in a pandemic requires speed, but without training and proficiency testing for those taking and reading samples, plus a robust process for ensuring appropriate actions follow a test result, SARS-CoV-2 self-testing by asymptomatic members of the public is unlikely to reduce transmission.

We have no empirical data to support mass SARS-CoV-2 screening, and home self-testing has not been evaluated. ${ }^{8}$ The December surge of infections in Liverpool, where trained testers screened a quarter of the population, was no lower than in other cities without screening. ${ }^{9}$ The effects of screening university students from December remain unclear, and data have not been made public. ${ }^{10}$ Care homes conducting asymptomatic testing have struggled to adhere to protocols and experienced no fewer outbreaks than care homes without asymptomatic testing. ${ }^{11}$ From early March, testing of millions of schoolchildren was accompanied by a short lived rise in the ascertainment of school age cases, but there is no evidence of change in the trajectory of case rates in older age groups, suggesting a lack of effect on onward transmission. ${ }^{12}$

\section{Wrong focus}

A key justification cited by government for mass testing of asymptomatic people at low risk is the assertion that "up to one third" of cases are symptomless, although it doesn't define what is meant by a case or by symptoms. Evidence is growing that transmission arises overwhelmingly from people with symptomatic infections and their contacts. ${ }^{13} 14$ The priority continues to be improving the testing programme for everyone with symptoms, no matter how minor or non-specific, and all their contacts. From 31 March 2021 it became policy in England for contacts of someone who has tested positive for covid-19 to have polymerase chain reaction (PCR) tests.

In addition to concerns about the cost and ineffectiveness of asymptomatic testing, self-reported results from asymptomatic people are already skewing nationwide data on test numbers, cases, and positivity rates, making trends harder to interpret. False positive results will be a problem when prevalence is low, even with PCR confirmation. And the temptation for people with symptoms to opt for unsupervised, rapid, and lower sensitivity self-testing may lead to false reassurance, as happens with other screening, ${ }^{15}$ leading to potential increases in transmission.

The UK is an outlier globally in placing such emphasis on asymptomatic testing. From May 2020, ministers focused their efforts on reaching targets for test numbers, creating centrally commissioned "lighthouse" laboratories and disregarding the quality of the tests or of the overall programme. ${ }^{416}$ They also commissioned a separate initiative for evaluating rapid tests, ${ }^{17}$ bypassing highly effective and flexible processes and expertis $\mathrm{e}^{18}$ both in developing screening programmes-the UK National Screening Programmes-and in evaluating diagnostic tests-for example, the medtech and in vitro diagnostics cooperatives funded by the National Institute for Health Research. The challenge was framed as "find a valid test and roll it out as quickly as possible" rather than "devise best systems for using testing to help contain the pandemic."

The issue is not, and never has been, about whether to test but about how to do it most effectively. ${ }^{19}$ The World Health Organization has never advised testing low risk people. The EU Council advice on rapid tests ${ }^{20}$ focuses on those with high pre-test probability, such as contacts of cases or where test positivity rates are $>10 \%$. The US Centers for Disease Control and Prevention (CDC) is explicit on limitations of rapid tests in low prevalence settings and is careful to distinguish diagnostic uses from screening. ${ }^{21}$ Innova, the UK's preferred screening test, is not included on the EU or $\mathrm{CDC}$ recommended lists.

The challenge now is to use the past year's learning, the new laboratory capacity, and the availability of rapid tests to best effect. Current efforts are undermined by secrecy, ${ }^{10}$ quality failures, ${ }^{16}$ underused capacity, ${ }^{4}$ and a misplaced focus on low yield uses. Both the laboratories and the rapid tests could be targeted to deliver a substantially more effective and cost effective testing service founded 
on the public service principles of sound evaluation, strong ethics, high quality, and full transparency.

Competing interests: The BMJ has judged that there are no disqualifying financial ties to commercial companies. The authors declare the following other interests: MG is a former member of UK National Screening Committee. The BMJ policy on financial interests is here: https:/www.bmj.com/sites/default/files/attachments/resources/2016/03/16-current-bmj-education-coi-form.pdf.

Provenance and peer review: Commissioned; not externally peer reviewed.

1 lacobucci G, Coombes R. Covid-19: Government plans to spend f100bn on expanding testing to 10 million a day. BMJ2020;370:m3520. . doi: 10.1136/bmj.m3520 pmid: 32907851

2 Department of Health and Social Care. New campaign urges public to get tested twice a week. Press release, 9 Apr 2021. https://www.gov.uk/government/news/new-campaign-urges-publicto-get-tested-twice-a-week

3 Our World in Data. Tests conducted per new confirmed case of covid-19.17 Apr 2021. https://ourworldindata.org/grapher/tests-per-confirmed-case-daily-smoothed?tab=chart\&country $=$ GBR $\sim$ DNK FRA DEU FIN JPN ESP $\sim$ USA $\sim$ SVK

4 House of Commons Public Accounts Select Committee. Test, track \& trace (part 1). Forty-seventh report of session 2019-21. 2021. https://committees.parliament.uk/publications/4976/documents/50058/default/

5 Cancer of the cervix: death by incompetence. Lancet 1985;2:363-4.pmid: 2862517

6 Sasieni P, Cuzick J, Farmery E. Accelerated decline in cervical cancer mortality in England and Wales. Lancet 1995;346:1566-7. doi: 10.1016/S0140-6736(95)92099-4 pmid: 7491080

7 Raffle A, Mackie A, Gray JAM. Case study 2.1: phenylketonuria screening: development of a system. In: Screening: evidence and practice. Oxford University Press, 2017.

8 Dinnes J, Deeks JJ, Adriano A, etalCochrane COVID-19 Diagnostic Test Accuracy Group. Rapid, point-of-care antigen and molecular-based tests for diagnosis of SARS-CoV-2 infection. Cochrane Database Syst Rev 2020;8:CD013705.pmid: 32845525

9 Liverpool covid-19 community testing pilot-interim evaluation report. 2020. https://www.liverpool.ac.uk/media/livacuk/coronavirus/Liverpool,Community,Testing,Pilot,Interim,Evaluation.pdf

10 lacobucci G. Covid-19: Mass testing at UK universities is haphazard and unscientific, finds BMJ investigation. BMJ2021;372:n848. doi: 10.1136/bmj.n848 pmid: 33789865

11 Tulloch J, Micocci M, Buckle P, etal. Enhanced lateral flow testing strategies in care homes are associated with poor adherence and were insufficient to prevent covid-19 outbreaks: results from a mixed methods implementation study.SSRN2021. [Preprint.] doi: 10.2139/ssrn.3822257

12 Independent Scientific Advisory Group. Weekly briefing 26 Mar 2021. https://www. independentsage.org/weekly-briefing-26th-march-2021/

13 Buitrago-Garcia D, Egli-Gany D, Counotte MJ, etal. Occurrence and transmission potential of asymptomatic and presymptomatic SARS-CoV-2 infections: a living systematic review and meta-analysis. PLoS Med 2020;17:e1003346. doi: 10.1371/journal.pmed.1003346 pmid: 32960881

14 Park SY, Kim YM, Yi S, etal. Coronavirus disease outbreak in call center, South Korea. Emerg Infect Dis 2020;26:1666-70. doi: 10.3201/eid2608.201274 pmid: 32324530

15 Henry RL, Boulton TJ, Roddick LG. False negative results on newborn screening for cystic fibrosis. J Paediatr Child Health 1990;26:150-1. doi: 10.1111/j.1440-1754.1990.tb02413.x pmid: 2206615

16 BBC. Undercover: inside the Covid testing lab. Panorama 29 Mar 2021.

https://www.bbc.co.uk/iplayer/episode/m000tajj/panorama-undercover-inside-the-covid-testinglab

17 Department of Health and Social Care. Protocol for evaluation of rapid diagnostic assays for specific SARS-CoV-2 antigens (lateral flow devices). https:/www.gov.uk/government/publications/assessment-and-procurement-of-coronavirus-covid-19-tests/protocol-for-evaluation-ofrapid-diagnostic-assays-for-specific-sars-cov-2-antigens-lateral-flow-devices

18 Hogarth S, Löblová O. Regulatory niches: diagnostic reform as a process of fragmented expansion. Evidence from the UK 1990-2018. Soc Sci Med 2020;113363. doi: 10.1016/j.socscimed.2020.113363 pmid: 32980173

19 Raffle A, Taylor-Phillips S, Sitch A. Mapping the outcomes of covid-19 testing reveals the best opportunities for system improvement. BMJ Opinion 9 Apr 2021. https://blogs.bmj.com/bmj/2021/04/09/mapping-the-outcomes-of-covid-19-testing-programmesreveals-the-best-opportunities-for-improvement/

20 Council of the European Union. Council recommendation on a common framework for the use and validation of rapid antigen tests and the mutual recognition of COVID-19 test results in the EU. 2021. https://data.consilium.europa.eu/doc/document/ST-5451-2021-INIT/en/pdf

21 CDC. 24/7 Saving lives, protecting people. Overview of testing for SARS-CoV-2. https://www.cdc.gov/coronavirus/2019-ncov/hcp/testing-overview.html\#Testinglnfection

This article is made freely available for use in accordance with BMJ's website terms and conditions for the duration of the covid-19 pandemic or until otherwise determined by BMJ. You may use, download and print the article for any lawful, non-commercial purpose (including text and data mining) provided that all copyright notices and trade marks are retained. 